NBER WORKING PAPER SERIES

PRIZES FOR BASIC RESEARCH -- HUMAN CAPITAL, ECONOMIC MIGHT AND
THE SHADOW OF HISTORY

Joshua Aizenman

Ilan Noy

Working Paper 12226

http://www.nber.org/papers/w12226

\author{
NATIONAL BUREAU OF ECONOMIC RESEARCH \\ 1050 Massachusetts Avenue \\ Cambridge, MA 02138
}

May 2006

We would like to thank Arnaud Dellis, Carlos Dobkin, Reuven Glick, Tim Halliday, Kyle Hampton, Lori Kletzer, Justin Marion, Andy Mason, Katya Sherstyuk, Mark Spiegel, Xiaojun Wang, John Williams, Donald Wittman and the seminar participants at UCSC, UHM and SF FED for their comments and suggestions; and Maxim Belenkiy, Jake Kendall and Yan Zhou for excellent research assistance. Useful comments by two anonymous reviewers are gratefully acknowledged. Any errors are ours. The views expressed herein are those of the author(s) and do not necessarily reflect the views of the National Bureau of Economic Research.

(C) 2006 by Joshua Aizenman and Ilan Noy. All rights reserved. Short sections of text, not to exceed two paragraphs, may be quoted without explicit permission provided that full credit, including $\odot$ notice, is given to the source. 
Prizes for Basic Research -- Human Capital, Economic Might and the Shadow of History

Joshua Aizenman and Ilan Noy

NBER Working Paper No. 12226

May 2006, Revised May 2007

JEL No. F15,F21,O3,N4

\begin{abstract}
$\underline{\text { ABSTRACT }}$
This paper studies the impact of several factors on the geographical distribution of basic scientific research across countries and time, and explains the dynamics of the process that has resulted in the United States becoming the undisputed leader in basic research. Our study is based on the records of major scientific awards, and on data dealing with global economic and historical trends. We investigate the degree to which scale or threshold effects account for the number of major prizes (Nobel, Fields, Kyoto, Wolf) won by different countries. We constructed a stylized model, predicting that lagged relative GDP of a country relative to the GDP of all countries engaging in basic research is an important explanatory variable of a country?s share of prizes. Scale effects imply that the association between the GDP share of a country and its prize share can be logistic -- above a certain threshold, there is a take-off range, where the prize share increases at an accelerating rate relative to the GDP share of the country, until it reaches "maturity" stage. Our empirical research findings confirm the importance of lagged relative GDP in accounting for a country's prize shares, and the presence of a "winner-takes-all" scale effect benefiting the leader. We found that U.S. basic research take-off started during the 1920s, with this research being done in the United States by U.S. scholars, prior to the immigration of scientists after Hitler's rise to power in Germany (1932-33). This is consistent with the notion that World War II set in motion forces that did not start, but hastened, the U.S. take-off, triggering immigration that contributed to the speed and intensity of U.S. research dominance. Using more recent data, we also documented the growing importance of countries that used to be at the periphery of global research, but are now possibly advancing towards the take-off stage.
\end{abstract}

Joshua Aizenman

Department of Economics; E2

1156 High St.

University of California, Santa Cruz

Santa Cruz, CA 95064

and NBER

jaizen@cats.ucsc.edu

Ilan Noy

Saunders Hall 542

2424 Maile Way

University of Hawaii, Manoa

Honolulu, HI 96822

noy@hawaii.edu 


\section{Prizes for Basic Research -}

\section{Human Capital, Economic Might and the Shadow of History}

This paper studies the impact of a variety of factors on the geographical distribution of basic scientific research across countries and time. Our goal is to explain the dynamics of the process that has resulted in the United States becoming the leader in basic research, and to identify factors that may shape the future patterns of global research. Understanding creativity and pathbreaking scientific research remains a black box. Given the absence of detailed information on networks of scientific research, and the effort associated with these networks, we relied on the records of major scientific awards, and on data dealing with global economic and historical trends. The cumulative records of major prizes included more than one hundred years of Nobel laureates in chemistry, medicine and physics, as well as the significant, albeit shorter, records of the Fields Medal, Kyoto and Wolf Prizes for basic research. We used this information to study the degree to which scale or threshold effects account for a country's share of major prizes.

When collecting and processing this information, we recognized the time lag between the actual research to the time when the prize was awarded, and the likelihood that the migration of scholars resulted in a discrepancy between the country of residence at award time and the country where the research was actually carried out. We dealt with these complications by compiling two data sets, dubbed award time and research time. Each prize was first recorded at the time and place where the awarded research was actually done (research time). It was then recorded at the time the award was presented, crediting it to the scholar's actual place of residence at award time. We used both data sets to infer the average lags between conducting research and receiving the award, in order to define more accurately the patterns of migration and infer the factors explaining global patterns of basic research.

Figure 1A, which focuses on award time, plots the averages of shares of Nobel Prizes for science (chemistry, medicine and physics) during the twentieth century, where the time unit is composed of five-year segments starting 1900-1904. The most dramatic development in this figure is the take-off of the U.S. share, starting from $0 \%$ in 1900 and reaching about $70 \%$ by the end of the century. Figure 2 plots the U.S. GDP, as share of total GDP of all countries for which at least ten science Nobel Prizes were awarded from 1900 to 2005, and the U.S. share of Nobel Prizes for sciences, where GDP share lags by two decades (reflecting the average gap between research time and award time). The fitted line in figure 2 is a third-order polynomial. 
These figures suggest that the U.S. take-off was closely linked to the sizable increase in the U.S. GDP share, and to the decline in the GDP share of Germany. The purpose of our paper was to analyze the factors accounting for these dramatic changes systematically, putting these factors in the context of a model that provides possible links between relative GDPs and prize shares, in the presence of scale effects associated with scientific research.

The starting point of our analysis is the conjecture that the U.S. basic research take-off and its present leadership position is the direct outcome of the collapse of the research position of Germany, which was the research leader at the beginning of the twentieth century. Using both research-time and award-time data sets, we examined this conjecture in detail, a procedure that was essential, both because of the lags between research and award times (two decades on average) and because of the migration of prominent scholars resulting from historical events. These concerns were crucial to our attempts to identify the impact of World War II on patterns of basic research. Using the research-time data allowed us to identify the timing of the actual research take-offs in several countries, timing that would have been blurred had only the awardtime data been used. Examining the data, we inferred that attributing the research take-off of the U.S. to the breakdown of research in Germany is only half the story.

U.S. basic research take-off started during the first third of the twentieth century. This research was done in the United States by U.S. scholars, prior to the immigration of gifted scientists before and during World War II. As is shown in table 1a and figure 6a, U.S. prize share using the research time panel was about $15 \%$ in the early $1900 \mathrm{~s}$, over $25 \%$ in the $1920 \mathrm{~s}$, and over $35 \%$ in the 1930 s, reflecting research done in the United States prior to the sizable immigration triggered by Hitler. These observations reflect both the average two-decade gap in time between the research and the awards, and the timing of immigration of prominent scholars. The U.S. take-off reached the maturity stage during the 1940s through the 1960s. The 1930s was the watershed decade, where the United States emerged as the basic research leader, due both to the scientific achievements of U.S. scholars, and to the sharp decline of research in Germany. World War II set in motion forces that hastened the U.S. take-off, triggering immigration patterns that accelerated and intensified this process.

Another goal of our work was to increase our understanding of the linkage between basic research and economic power. Figure 2 suggests that the association between GDP at research time, and prize shares two decades hence, i.e. at award time, is logistic. This observation is 
consistent with the predictions of the stylized model described in the next section, explaining countries' prize shares, when scale effects characterize the production of basic research. Specifically, the model predicts that lagged relative GDP of a country, relative to that of other countries engaging in basic research, is an important explanatory variable of a country's share of prizes. Scale effects imply that the association between the GDP share of a country and its prize share tends to be logistic - that is, above a certain threshold there is a take-off range, where the prize share increases at an accelerating rate, until it reaches maturity stage.

Simulating a simple version of our model suggested that the model fitted the first part of the U.S. basic research take-off, though it underestimated its momentum (see figure 5). ${ }^{1}$ Our empirical analysis confirmed the importance of lagged relative GDP in accounting for a country's prize shares, and the presence of a winner-takes-all scale effect, reflecting a convex association between income and basic research. Apparently, the winner-takes-all effect was reinforced even further by immigration patterns: from 1936 onward, 73 of the U.S. Nobel laureates were immigrants from other countries, amounting to $18.2 \%$ of the total Nobel Prizes in basic research awarded to all countries during that time period. The corresponding Nobel awards gained by immigrants to other major recipient countries are 15 for the UK, 12 for Switzerland, and only 4 for Germany (see table 1A). During that same period, 26 Nobel laureates were of German, 8 of Austrian, 7 of British, 7 of Canadian, 6 of Hungarian, 5 of Polish, and 4 of Russian origin (see table 1B for more details). ${ }^{2}$ Our analysis is consistent with the notion that World War II set in motion forces that hastened the U.S. take-off, suggesting that migration patterns accelerated this process.

An additional finding of our analysis was that, ceteris paribus, the return toward a more symmetric configuration among leading industrial countries may eventually reverse some of the trends observed during the twentieth century. A glimpse into this possibility is provided in figure 1B, which plots the combined prize share of all countries, excepting Europe and the United States, hence referred to as AOC (All Other Countries). When reading this graph, one should keep in mind the two-decade average lag between the actual research and the award for it. Figure

\footnotetext{
${ }^{1}$ There was, however, an intriguing discontinuity in the U.S. basic research take-off: the U.S. prize shares (using research time) were below $40 \%$ during most of the first third of the twentieth century, but well above $50 \%$ after 1940. Using the award time data, the U.S. prize shares were either below $30 \%$ during most of that period, or well above $50 \%$ after 1940 .

${ }^{2}$ Hence, the net immigration of Nobel laureates for $1936-2005$ was 73 to the U.S., 12 to Switzerland, 8 to the UK, 1 from France, 4 from Russia, 5 from Poland, 5 from China, 6 from Hungary, 7 from Canada, 8 from Austria, 21 from Germany.
} 
1B suggests two instances of impending AOC take-offs in the last 70 years: the first is 19401960 (reflecting research done, approximately, during 1920-1940), and 1990-2005 (reflecting research done during 1970-1985). The first take-off was apparently aborted due to the upheaval of World War II. These trends stand out even more clearly when one looks at the aggregation of the Nobel with other prizes for basic research (see figure 1B).

Related questions were investigated in the literature on economic development. In a number of intriguing studies, carried out by Davis and Weinstein (2002 and 2004) on the longterm distribution of economic activity within Japan, for instance, even very large temporary shocks to urban areas seemed to have no long-run impact on city size. When examining this question in the context of the intense Allied bombing of Japanese cities and industries in World War II, they found that, even in the aftermath of severe shocks, a city typically recovered not only its population and its share of aggregate manufacturing, but also the composition of specific industries it had had before. Hence, they did not find support for path dependency, which was frequently linked to returns to scale (see Krugman, 1991, and David, 2000). To the best of our knowledge, there has been very little research on these questions in the context of basic scientific research. The tremendous global shocks of the twentieth century provide the background to our investigation, provoking questions akin to the ones studied by Davis and Weinstein regarding the degree to which economic power and the world wars have affected basic scientific research in enduring ways.

Section 1 outlines a stylized model explaining key determinants of basic research.

Section 2 discusses the data used in the paper. Section 3 summarizes the empirical regularities and the results of regressions, explaining the changing prize shares of various countries. In our concluding remarks in section 4 , we have outlined important issues that are beyond the scope of the present paper, such as the role of public versus private funding of basic research, the quality of governance, the changing roles of research networks and the diffusion of information technology.

\section{Stylized model of key determinants of basic research.}

This section outlines the stylized model used to identify the variables applied in our empirical study. We modeled prizes awarded for basic research as the outcome of a periodic contest between prominent recent contributions. Since prizes are not awarded posthumously, 
there is a time limit set by the scholars' life cycles. The intertemporal importance of major contributions is determined by the speed of knowledge diffusion. As we did not have a tractable way of comparing the relative importance of the major contributions, we adopted a simple threshold approach: all major scientific contributions of the same period were treated as equal candidates for winning the prize contest. The arrival rate of major contributions in a country depends on the stock of knowledge in that country, potentially interacting with the global stock of knowledge in non-linear ways, due to scale and networking effects. Such knowledge, dubbed "human capital," evolves as the outcome of invested resources, adjusted for the depreciation caused by aging, and/or such calamities as wars or natural disasters. ${ }^{3}$ The investment in human capital depends positively on the scale of the economy that supports the research, e.g. real GDP, and/or real GDP pre capita.

A key aspect of scientific research is the presence of returns to scale, possibly due to fixed costs and networking effects. Basic research may lack immediate commercial use, yet it is associated with significant fixed set-up costs (costs of setting laboratories, running experiments, and disseminating results). These costs may be prohibitive enough to be supported only by a few affluent countries, in a few well-endowed centers. One therefore expects these centers to be magnets for scientific work, leading to scale economics and agglomeration (see CERN in Switzerland, ${ }^{4}$ or the Brookhaven National Laboratory in the United States ${ }^{5}$ ). Furthermore, research frequently benefits from peer interaction, leading to network externalities when doubling the number of scholars in the network may more than double the productivity of the network. ${ }^{6}, \quad$ These considerations suggest that doubling the investment in knowledge more than

\footnotetext{
${ }^{3}$ Human capital is the stock of expertise, knowledge, and skill embodied in an individual as a result of education, training, and experience that raises their productivity (on conceptualization and measurement of human capital, see Becker, 1975).

${ }^{4}$ CERN (French for European Nuclear Research Centre) is located near Geneva. Its recent purchase of Europe's flagship particle accelerator (LHC) has been associated with capital costs of more than \$2 B. A Why Geneva Web page credits the proximity of CERN to making Geneva a research hub: "Many of the no fewer than 44 Nobel prizes awarded to residents of Geneva came as a result of the presence of CERN in the city" (see $\mathrm{http} / / / \mathrm{www} . \mathrm{geneva.ch/f/lhc.htm}$ ). The presence of prize winning immigrants is also evident in our table 1A and 1B. ${ }_{5}^{5}$ Established in 1947 on Long Island, Upton, New York, Brookhaven is a multi-program national laboratory, operated by Brookhaven Science Associates for the U.S. Department of Energy (DOE). Six Nobel prizes have been awarded for discoveries made at the laboratory. Brookhaven has a staff of approximately 3,000 scientists, engineers, technicians and support staff, and over 4,000 guest researchers annually (see http://www.bnl.gov/world/ ).

${ }^{6}$ Network externalities refer to the effects of other users on an individual user of a service. Positive network externalities exist if the benefits are an increasing function of the number of other users. For example, a network connecting $\mathrm{n}$ scholars entails potential $0.5 \mathrm{n}(\mathrm{n}-1)$ pair interactions. If the productivity of the network depends linearly on pair interactions, doubling the network would almost quadruple its productivity. This effect is further
} 
double the efficacy of research. Further magnification of these effects occurs when scholars are mobile; this implies that research centers located in countries that are friendlier to immigrants are attractors of talent, and end up as key research hubs. Conversely, research hubs may be destroyed rapidly if tolerance towards immigrants diminishes, or if calamities reduce the resources available to basic research, as has been vividly illustrated in the first half of the twentieth century.

Here, we focus on the degree to which macroeconomic variables, interacting with historical events, explain the cross-country distribution of basic research, quantified by the countries' share of Nobel and other major scientific prizes. We concentrated on countries that have reached the threshold level of development necessary for meaningful investment in basic research. We refrained from modeling the micro details of the network effects associated with scientific research. We considered a stylistic model, where possible scale effects might imply that the arrival rate of scientific contributions depends in a non-linear manner on human capital. In short, we assume the stock of human capital changes with a simple accumulation rule, where a fraction of the real GDP is invested in forming future human capital.

We sketched the following model for prizes:

\section{$\underline{\text { Notation }}$}

$\phi_{i, t}=$ number of major contributions occurring in country $i$ during time $t$ that may qualify for a prize in a given discipline, scaled by the importance of the contribution.

$\phi_{i, t-k}^{n}=$ contributions credited to country i dating to period t-k, net of the contributions that already won prizes (i.e., $\phi_{i, t-k}^{n}$ is obtained by adjusting $\phi_{i, t-k}$ downward by the contributions that were already rewarded).

$\Phi_{i, t}=\sum_{k=0}^{T} \phi_{i, t-k}^{n} d_{t-k}=$ stock of contributions credited to country $i$ that may qualify for a prize at time $t$ (net of contributions that were already awarded prizes). The stock was obtained by applying the discount factor $d_{k}$ to contributions going back $T$ years ago. $T$, the backward-looking

magnified if, as is frequently the case, basic experimental research needs a sizable crew of scholars, well above pair interactions.

${ }^{7}$ Wuchty et al. (2007) document the increasing importance of teams in generating scientific peer-reviewed research and patents. 
discounting horizon, was bounded by scholars' life expectancies, and $d_{k}$ was determined by the speed of diffusion of new contributions, apparently characterized by an inverted $U$ shape.

Assuming that the size of the prizes that won awards was small, relative to the pool of major new contributions, and that all contributions were entered identically, winning the prize was akin to sampling with replacement. Hence, the outcome of the Nobel contest could be approximated by generalized Bernoulli trials, with their convenient Gaussian properties.

Subject to all these assumptions, the probability of winning a prize at time $t$ by country $i$ in a given discipline, $s_{i, t}$, was approximated by

$$
S_{i, t}=\frac{\Phi_{i, t}}{\sum_{i=1}^{N} \Phi_{i, t}},
$$

where $N$ is the number of countries engaging in active basic research. We parameterized the flows of new contributions of country $i$ as a proportion $k_{i}$ of the human capital index, $\left[H_{i, t}\right]^{\beta}$;

$$
\text { (2) } \phi_{i, t}=k_{i}\left[H_{i, t}\right]^{\beta} \text {, }
$$

where $\beta>0$ captures any scale effects. More generally, complementarities between local and global knowledge were captured by a CES aggregator:

(2') $\left.\quad \phi_{i, t}=k_{i}\left\{a_{i}\left[H_{i, t}\right\}+\left(1-a_{i}\right)\left[\bar{H}_{t}\right\}\right\}^{\prime}\right\}^{\frac{\beta}{\gamma}}$

where $\bar{H}_{t}$ denotes the foreign human capital (i.e., the sum of the human capital of all other countries), and 1- $a$ measures the externality associated with research attributed to foreign human capital ( $a=1$ denotes the case of no externality as in equation 2 ). The human capital of country $i$ follows a simple accumulation rule: a fraction $c_{i, t}$ the real GDP is invested into forming future human capital; ${ }^{8}$ fraction $\delta_{i, t}$ depreciates, due to aging, wars, or natural disasters.

\footnotetext{
${ }^{8}$ If basic research is "luxury activity," $c_{i, t}$ would increase with the GDP per Capita. In these circumstances, our model predicts that the prize share of a country would depend positively on lagged GDP, and negatively on lagged population.
} 


$$
H_{i, t}=\left(1-\delta_{i, t}\right) H_{i, t-1}+c_{i, t} Y_{i, t-1} .
$$

To illustrate the model, we first considered the case where periods were set to cover a generation of scientists, e.g. 25 years, such that $\delta_{i, t}=1$ (for all $i$ and $t$ ); hence

$$
H_{i, t}=c_{i, t} Y_{i, t-1}
$$

We aggregated all the countries doing frontier research into 2 blocks, e.g. the United States and AOC, and assume that the AOC block was composed of $n$ symmetric countries. These assumptions allowed us to solve the prize share of the United States as a function of the lagged real U.S. GDP relative to all other countries GDP, denoted by $\Gamma$ (i.e. $\Gamma=Y_{U S,-1} / Y_{A O C,-1}$ ). Assuming identical productivity structure across countries (i.e. both blocks have the same $k, c$, and $a$ ), we can infer that:

$$
S_{U S}=\frac{\left\{a \Gamma^{\gamma}+(1-a)\right\}^{\frac{\beta}{\gamma}}}{\left\{a \Gamma^{\gamma}+(1-a)\right\}^{\frac{\beta}{\gamma}}+n\left\{a(1 / n)^{\gamma}+(1-a)(\Gamma+(n-1) / n)^{\gamma}\right\}^{\frac{\beta}{\gamma}}}
$$

A useful benchmark is the case where $a=1$, corresponding to the absence of the global human capital externality:

$$
S_{U S}=\frac{\Gamma^{\beta}}{\Gamma^{\beta}+n^{1-\beta}}
$$

Figure 3a plots the U.S. share of the prizes predicted by our model as a function of the relative GDP share of the U.S./AOC. The bold curve corresponds to the benchmark case of two country groups - the United States and a uniform AOC $(n=1)$, the absence of foreign human capital externality $(a=1)$, and significant scale effects $(\beta=2)$. The solid curve to the left of the bold curve modifies the benchmark by considering the case where AOC are composed of two 
symmetric countries $(\mathrm{n}=2 ; a=1)$. Note that a more fractured composition of AOC reduces the research effectiveness there, thereby increasing the U.S. prize share. The dotted curve modifies the benchmark by allowing modest human capital externality $(\mathrm{n}=1, a=0.95)$. The latter increases the share of the smaller block at the expense of the larger block. Figure $3 \mathrm{~b}$ plots the same curves in the absence of returns to scale in research $(\beta=1)$. Removing scale effects considerably mitigates the prize share of the larger block (thus increasing the share of the smaller block). It also implies simple additivity of the countries comprising the block of AOC, and eliminates the inflection point.

The presence of scale effects implies that the association between the relative GDP shares and the prize share of the United States resembles a logistic curve. In fact, (4') demonstrates that for relatively small countries, the initial effect of higher GDP share on the prize share is nil: $d s_{U S} / d \Gamma_{\mid \Gamma=0}=0$ for $\beta>1$. As the GDP share grows further, it increases the prize share at an accelerating rate, reflecting the growing impact of scale effects. This acceleration reaches its peak and the inflection point when the U.S. relative GDP equals $\widetilde{\Gamma}=\left[n^{1-\beta}(\beta-1) /(\beta+1)\right]^{1 / \beta}$.

From then on, further increase of the GDP share increase the prize share at diminishing rates. ${ }^{9}$ It also follows that with greater scale effects, a higher threshold of relative GDP is needed in order to reach the take-off range associated with the accelerating increase in prize share. Once this range has been reached, the take-off is faster. This result is illustrated in figure $4 \mathrm{a}$, which describes the case where the scale effect is magnified from 2 (the bold curve) to 4 (the solid curve) - the curves are drawn for the cases where AOC is composed of a unique country. Figure $4 \mathrm{~b}$ replicates this for instances when the AOC is fractured into two symmetric countries. As one may expect, it demonstrates that the large country (the United States) takes off at a lower relative share.

Figure 5 plots the U.S. Nobel shares / lagged U.S. share of World GDP during the twentieth century with the corresponding shares obtained from a simulated version of the stylistic model. While the model captures the first part of the take-off, it underestimates the speed at which the United States reaches the mature stage. Our empirical work suggests that some of the

\footnotetext{
${ }^{9}$ These results follow from the observations that $d s_{U S} / d \Gamma=\frac{\beta \Gamma^{\beta-1} n^{1-\beta}}{\left[\Gamma^{\beta}+n^{1-\beta}\right]^{2}}$; and $\operatorname{sign}\left[d^{2} s_{U S} / d \Gamma^{2}\right]=\operatorname{sign}\left[(\beta-1) n^{1-\beta}-(\beta+1) \Gamma^{\beta}\right]$.
} 
fast take-off of the United States may be accounted for by the effects of World War II, thus disrupting research networks in favor of the United States. ${ }^{10}$

The above model offers several predictions, some of which are summarized below:

- The GDP of a country relative to the GDP of other countries engaging in basic research is an important explanatory variable of that country's share of prizes.

- Scale effects imply that above a certain threshold, there is a take-off range, where the prize share increases at an accelerating rate with the relative GDP share of a country, until it reaches maturity stage.

- In the presence of scale effects, a more fractured AOC block reduces the relative GDP needed to induce a prize-share take-off.

- Greater fluidity of the flow of information and scholars across countries (possibly due to the proliferation of IT technology and the drop of airfares) increases the positive externality associated with foreign human capital, thereby mitigating the advantages enjoyed by the large block - advantages induced by scale effects.

\section{Data}

Our data were generally taken from two sources: First, data on prizes were obtained from the official websites of the respective prizes; when the relevant biographical data were not available on the prize's website, we obtained additional information from other on-line sources. All the macroeconomic data were taken from the OECD's The World Economy: Historical Statistics CD-ROM, based on data compiled by Maddison (2003).

For the Nobel Prizes, we noted the country in which each recipient resided at the time of the award. We also recorded the country location and the decade in which the research for which the award was given was conducted - these data were obtained by reading the narrative biographical description of each awardee. In case no description was provided (as for some of the early Nobel awards) we obtained the data from other sources. Our sample covers 509 Nobel Prizes awarded in chemistry, medicine and physics from 1901 to 2005. We did not record the

\footnotetext{
${ }^{10}$ Other obvious shortcomings of this paper are that our simulation assumes that the key parameters (the scale effects, number of countries engaged in basic research, etc.) have been constant throughout the twentieth century, and that we imposed an assumption of equal productivity for all the relevant countries.
} 
economics, peace and literature awards. ${ }^{11}$ We recorded the same variables for the following prizes: the Wolf Prize in agriculture, chemistry, mathematics, medicine and physics (199 prizes awarded annually since 1978); the Kyoto Prize in advanced technology and basic sciences (47 prizes awarded annually since 1985); and the Fields Medal in mathematics (44 prizes awarded every four years since 1936).

We constructed two separate panel data sets. The first, dubbed award-time data set, includes five-year totals for prizes awarded, for each country in five-year segments (observations). In this data set, each prize is recorded for the year in which it was awarded and the location of the researcher/s at the time of the award. In the second data set, dubbed researchtime set, we compiled a panel of observations for each country in each decade in which each prize was recorded for the time and place when the most important awarded research was done. The reason for using decades in the research time versus five-year segments in the award time is that each award was given at a precise time; however, the award recognizes research that was conducted over a prolonged gestation period, often around a decade long. Consequently, the data did not make it possible for us to identify the exact year of the research for which the prize is presented, only the decade and place of that research. Hence, a prize awarded for research done in Germany, but awarded to a scientist who was residing in the UK 20 years later, at the time of the award, will be counted for the UK for the five-year data set (award-time). For the ten-year data set, the prize would be credited to Germany, two decades before the award. ${ }^{12}$

Since for many of the smaller countries, very few awards have been given over the past century, we recorded these data in ten separate country groups. We aggregated the data according to cultural and geographical affinity: i.e. the United States; the United Kingdom; Germany; France; Scandinavia; other European countries; Australia and Canada; Japan; the USSR (and

\footnotetext{
${ }^{11}$ A few papers have looked at the same Nobel data from a microperspective (without aggregation) in research examining the life-cycle characteristics of innovation. See, in particular, Jones (2005) and Weinberg and Galenson (2005).

${ }^{12}$ This implies that with our ten-year data set, we are controlling for the effect of immigration (see discussion on the importance of immigration in the introduction to this paper). Since results for the two data sets are very similar, we argue that while immigration is important, it cannot be the only reason for the U.S. scale effect we observed.
} 
later Russia); and all other countries (including all countries that received at least one prize). ${ }^{13}$ Correlations between the different prize measures are provided in appendix B.

For the macroeconomic data, we used GDP (in constant 1990 international dollars), and population measures taken from Maddison (2003). These data are averaged over five and ten years for the corresponding data panels. To measure World War I and World War II casualties, we obtained data on war deaths (both civilian and military) and divided those by the population in each country. ${ }^{14}$ Appendix B details the data sources and provides descriptive statistics.

\section{Empirical results}

We constructed an empirical model that is based on equation (4). Since we were interested in the amount of generated basic research, as proxied by the amount of prizes won, we stipulated a benchmark model in which the share of each country's prizes (out of the total global amount) depends on a country's income (GDP) and its population. ${ }^{15}$ Since GDP per capita might be the relevant income measure to approximate the amount of resources available for domestic $\mathrm{R} \& \mathrm{D}$ investment, the stipulated hypothesis was that the population variable has a negative coefficient.

Since the construction of the LHS variable (prize share) is censored on the left by zero, we estimate a standard Tobit, estimated by maximum likelihood. The model we estimated was the following:

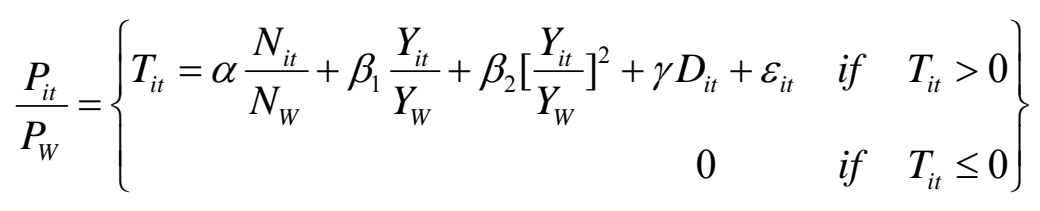

where $P_{i t} ; N_{i t} ; Y_{i t} ; P_{W} ; N_{W} ; Y_{W}$ are the total prizes $(P)$ credited to research done in country $i$ during period $t$ ( $t$ is typically two decades earlier than the time the prize was awarded), the population $(N)$ and gross domestic product $(Y)$ for country $i$ and time $t$, or for the total world $(W)$ where the world is defined as all countries that have won prizes. In a number of specifications we also

\footnotetext{
${ }^{13}$ Our sample covers 509 Nobel prizes awarded in chemistry, medicine and physics during 1901-2005. The last, the all other countries, group received only 9 Nobel Prizes, less than $2 \%$ of the total awarded. This observation is consistent with the presence of the strong scale effects discussed above.

${ }^{14}$ The WWI casualties are attributed to 1916-1920, or 1911-1920 in the cases of the five- and ten-year data sets, respectively.

${ }^{15}$ The empirical model we employed is similar to that implemented by Bernard and Busse (2004) for predicting Olympics medal counts.
} 
included binary variables $\left(D_{i t}\right)$ or a measure of casualties from the world wars per country panel observation. For the error term, we assumed $\varepsilon_{i t} \sim N\left[0, \sigma^{2}\right]$.

In table 2, we reported the results of our benchmark specification, examining the impact of GDP and population on the incidence of prizes. Table 2A employs the ten-year research-time panel. We also estimated the same specifications for the five-year award-time panel; because of the observed lag between research and award, in table $2 \mathrm{~B}$, we lag the independent variables by four lags ( 20 years) for this data set. We confirmed the need to lag the independent macrovariables by estimating specifications for different lag structures and observing that the optimal lag is indeed 20 years. ${ }^{16}$

Results in columns 1-3 (tables 2A and 2B) demonstrate that the incidence of Nobel winnings is clearly positively associated with GDP and negatively associated with population (after controlling for GDP). Results in columns 4-6 (tables 2A and 2B) confirm the same associations with a different dependent variable: the total number of prizes (Nobel, Fields, Kyoto and Wolf) awarded for each country-period as a share of the total awards for that period.

In table 3, we presented the complete specifications examining the importance of scale effects. Since results were qualitatively the same across the research- and the award-time data sets when we used the proper lags on the conditioning variable, we then discussed the results, using the ten-year research-time panel. ${ }^{17}$ In column 1, table $3 \mathrm{~A}$, we added the square of GDP to our benchmark specification. The coefficient is statistically significant at the $99 \%$ confidence level, suggesting a clear incidence of scale effects. ${ }^{18}$ In column 2, we employed, instead, binary variables that examine whether Germany before World War I, and the United States after World War II are unique in their acquisition of prizes. Since we speculated there might be a home-team bias — at least for the Nobel Prize — we included a binary variable for Scandinavia. Pre-World War I Germany and post-World War II United States (with their coefficients significant at the

\footnotetext{
${ }^{16}$ We estimated the model with a variety of lag structures and in all cases the only coefficient that came out significant was the $(t-4)$ one - implying a lag of two decades. Results are available upon request.

${ }^{17} \mathrm{We}$ also report the results in the award-time panel.

${ }^{18}$ This finding contrasts with a recent work, Rose (2006), which failed to find scale effects in "the level of income, inflation, material well-being, health, education, the quality of a country's institutions, heterogeneity, and a number of different international indices and rankings."
} 
$1 \%$ level) are clearly unique cases. We found no evidence, however, of home-team bias and discarded this variable in all subsequent estimations. ${ }^{19}$

In column 3 (table 3A) we added the dummy for the post-World War II United States to the $(\mathrm{GDP})^{2}$ variable. Since the coefficient on $(\mathrm{GDP})^{2}$ is not significant once the U.S. post-World War II dummy is included, we concluded that the dynamic scale effects we obtained are completely driven by the impact of the U.S. presence in this competition. This is also evidenced by the fact that our fit measures did not improve when (GDP) ${ }^{2}$ was included in the specification (compare columns 2 and 3 in table 3A). These results carried through once we used the country share of total prizes (instead of the country share in Nobel Prizes) as our dependent variable in columns $4-6$ of table $3 \mathrm{~A}$.

Since we observed an increase in the share of prizes going to previously peripheral countries in the last two decades, we postulated that it was possible that the structure of the relationships we identified had recently changed. In table 4, column 1, we ran the same specification as in table 3B, column 1, but included additional interactions of all the coefficients with a 1975-2004 binary indicator. We found evidence of a change in the magnitude of the post1975 coefficients. The GDP variable seemed to have a smaller correlation with prize shares in the latter period, while the scale effect appeared to matter more than in the pre-1975 period. The importance of the relative population size also declined. ${ }^{20}$

Another interesting question was whether we would be able to identify scale effects in non-leading countries as well. In table 4 , column 2 , we reran the specification in table $3 \mathrm{~B}$, column 1, but excluded the U.S. observations from our data set. Interestingly, the GDP ${ }^{2}$ variable was no longer significant; this confirms our previous result that the scale effect we observed was apparently captured entirely by the leader.

We also investigated whether our results were driven by the destruction World War II wrought on continental Europe, and not by the U.S.-dominated scale effects we had observed. We found that the only significant effect could be found for a lag of three decades - i.e. deaths in the war negatively impact the viability of basic research about 30 years after the fact. This

\footnotetext{
${ }^{19}$ For the Kyoto prize, four awards (out of 46) were given to Japanese nationals, while for the Wolf eleven awards went to Israeli citizens (out of 199). In both cases, this appears to be somewhat more than was predicted by our empirical model (especially for the Wolf), but identification of a statistically robust finding of home bias was not possible in the aggregate data sets. The Fields Medal is awarded by an international organization (the International Mathematical Union) so the question of a home bias becomes largely mute. The Field Medal offices are located at the University of Toronto, but the medal was never given to a Canadian.

${ }^{20} \mathrm{We}$ thank one of the referees for suggesting this specification.
} 
result is not very robust, however; we find that the effect could be accounted for by non-linear changes in incomes or just by the rising post-war dominance of the United States. We concluded, not unlike Davis and Weinstein (2002 and 2004), that the destruction did not have a long-term statistically observable effect on the production of basic research. These results are presented in table $\mathrm{D}$ in the appendix.

Figure 6a reports the Nobel Prize shares of the United States in two distinct ways. The shaded curve, award time, reports the average Nobel share awarded to U.S. residents per decade in the twentieth century (it is obtained from the five-year panel described in the data section). The solid curve, i.e. real research time, reports the research share of the United States, during the actual decade of research, between the 1880s and the1970s, which was later credited with the Nobel Prize (it was obtained from the ten-year panel described in the data section). The difference between the two curves reflects the delay between the actual research, with an average of two decades, and the impact of scholars' mobility. The solid curve indicates that the U.S. basic research take-off, measured by actual research done in real research time, started in the 1920s and 1930s, and reached maturity stage between the 1940s and 1970s. Comparison of these two curves suggests that the first stage of the U.S. take-off occurred prior to the immigration of talent brought about by World War II. This immigration contributed to the speed and intensity of U.S. take-off. Applying a similar methodology, we reported the Nobel Prizes shares for Germany in figure $7 \mathrm{~b}$. It vividly shows the basic research leadership status of Germany from the 1890 s to the $1920 \mathrm{~s}$ - a status abruptly lost in the 1930s. Comparison of the two curves in figure $6 \mathrm{~b}$ reveals that the bulk of the actual basic research done in Germany during the 1920s was credited to other countries, as is suggested by the immigration patterns summarized in table 1. The 1930s was the watershed decade, when the United States emerged as the undisputed basic research leader.

\section{Concluding remarks}

Our empirical analysis confirms the importance of lagged relative GDP in accounting for prize shares, and the presence of a winner-takes-all scale effect. The relative GDP variable accounts for the prize shares of the non-leading countries, yet it falls short of accounting for the scale effects impacting the leading country. Intriguing events dominating the patterns of basic research over the last hundred years are the leadership role of Germany during the first two 
decades of the twentieth century, and the rapid U.S. take-off in the 1930s, which solidified the U.S. basic research leadership position shortly thereafter.

We close this paper with a number of concluding remarks and a discussion of some issues left open for future research. This paper investigated the process of producing basic research. We did not examine the link between successful basic research, private investment, the corporate sector's ability to appropriate results, and other possible social benefits. After all, basic research is rarely the end target and the economic literature has suggested a number of alternative desired goals for research. These issues have been examined before, albeit without producing any emerging consensus (for a recent survey, see Salter and Martin, 2001). The answers to some of these questions could be related to our own research on the preliminary stages of basic research, since one expects that it would be easier to fund basic research in countries with deeper spillover from basic research to private (or public) rents.

The interplay between the private and the public sectors in promoting basic research deserves more investigation. The basic research take-off of the United States happened during the first third of the twentieth century, when the involvement of public funding in basic research was limited. The solidification of the role of the United States as a hub of basic research happened later, at a time of greater involvement of the public sector in funding and directing of basic research. This observation is validated in figure 7, where the solid curve depicts the constant dollar involvement of the U.S. government in funding basic research by sectors. ${ }^{21}$ Obtaining more detailed information about private vs. public funding of basic research in various countries could potentially enable researchers to identify the role of public funding in the take-off process.

Besides public vs. private funding, other factors might also lead to differing magnitudes of the scale effects in basic research across countries and time. In-depth studies of the role of research networks, possibly using empirical methodologies similar to the Erdös number project, might shed some light on these questions.

The recent diffusion of information technology has led to cheaper means of communication, and reduced the coordination costs of conducting joint research across

\footnotetext{
${ }^{21}$ The point is exemplified by the growing role of NSF, NIH, and NASA, and is reinforced by the time lag between the actual research and the timing of awards. The NSF was established by the National Science Foundation Act of 1950. The NIH emerged out of the Laboratory of Hygiene, and was reorganized in 1930 by the Ransdell Act into the National Institutes of Health. NASA was established in 1958.
} 
geographical distance. The presence of these new technologies increases the spillovers from foreign to domestic research, as well as the possibility of greater cross-country collaboration. Whether the telecommunication revolution has indeed changed the calculus of basic research remains an open question for future research.

In conclusion, we would like to emphasize the inability of this kind of econometric inference to prove causality, and the limited predictive ability of correlations without the opportunity of conducting controlled experiments - see Lucas's (1976) critique of econometric policy evaluation. This is especially true in circumstances such as in our study, which dealt with the black box process associated with creativity. An obvious implication of our study is that, in the presence of scale effects, a critical size is a necessary condition for basic research take-off. While the evidence in this paper is consistent with the growing significance of countries that used to be at the periphery of global research, it is a mistake to equate economic take-off with basic research take-off, as it may confuse necessary and sufficient conditions. A loose interpretation of the U.S. experience is that the growing allegiance of public and private resources helped solidify and speed up basic research take-off. Yet, a growing body of economic research cautions us that the quality of public investment is determined by the overall quality of governance, transparency, contestability, and openness of the allocation process. These factors are essential to prevent the misuse of public funds as a means of redistributing political rents. ${ }^{22}$ One expects the same to apply to the evaluation of the role of public funds in enhancing basic research. Further investigation of all these issues is needed in order to provide us with better policy guidelines.

\footnotetext{
22 See Tanzi and Davoodi (1997), Everhart and Sumlinski (2001), and the reference therein. Everhart and Sumlinski (2001) concluded that “... corruption lowers the quality of public investment, and this poor quality public investment is associated with lower private investment."
} 


\section{Appendix - Data Sources and Descriptive Statistics}

\section{Table A - Data definitions and sources}

\begin{tabular}{|c|c|c|}
\hline Prizes & Data definition & Source \\
\hline Nobel & $\begin{array}{l}\text { Nobel Prize awards in chemistry, medicine and physics, } \\
1901-2005 .\end{array}$ & $\begin{array}{l}\text { http://nobelprize.org/ } \\
\text { http://www.almaz.com/nobel/ }\end{array}$ \\
\hline Wolf & $\begin{array}{l}\text { Wolf Foundation Prize awards in agriculture, chemistry, } \\
\text { mathematics, medicine and physics, 1978-2005. }\end{array}$ & http://www.wolffund.org.il/main.asp \\
\hline Kyoto & $\begin{array}{l}\text { Kyoto Prize awards in basic science and advanced } \\
\text { technology, 1985-2005. }\end{array}$ & http://www.kyotoprize.org/ \\
\hline Field & Fields medal in mathematics, 1936-2002. & http://www.mathunion.org/medals/Fields/ \\
\hline GDP & Gross domestic product in million 1990 international dollars. & Maddison (2003) \\
\hline POP & Population in thousands at mid-year & Maddison (2003) \\
\hline WW I casualties & Total casualties in World War I & http://www.infoplease.com/ipa/A0004617.html \\
\hline WW II casualties & Total casualties in World War II & http://www.secondworldwar.co.uk/casualty.html \\
\hline
\end{tabular}

\begin{tabular}{cccc} 
Table B - Descriptive statistics: & prizes & five-year data \\
\cline { 2 - 4 } Prizes & $\begin{array}{c}\text { Number of } \\
\text { prizes }\end{array}$ & $\begin{array}{c}\text { Mean of } \\
\text { observations }\end{array}$ & $\begin{array}{c}\text { STD of } \\
\text { observations }\end{array}$ \\
\hline Nobel & 509 & 2.42 & 4.49 \\
Wolf & 199 & 0.95 & 3.40 \\
Kyoto & 46 & 0.22 & 1.05 \\
Field & 44 & 0.21 & 0.61 \\
\hline
\end{tabular}

Table C — Prize correlations — five-year data set

\begin{tabular}{lccc}
\hline & Kyoto & Field & Wolf \\
\hline Nobel & 0.63 & 0.57 & 0.67 \\
Kyoto & 1 & 0.41 & 0.64 \\
Field & 0.41 & 1 & 0.54 \\
\hline
\end{tabular}


Table D - Regressions: world war casualties - ten-year research time data

\begin{tabular}{|c|c|c|c|c|c|}
\hline \multirow[t]{2}{*}{ LHS: } & \multicolumn{5}{|c|}{ Nobels } \\
\hline & (1) & (2) & (3) & (4) & (5) \\
\hline GDP/W & $\begin{array}{l}1.627^{* \star *} \\
(13.021)\end{array}$ & $\begin{array}{l}1.687^{* * *} \\
(13.433)\end{array}$ & $\begin{array}{l}1.705^{\star \star \star} \\
(13.631)\end{array}$ & $\begin{array}{r}0.594 \\
(1.839)\end{array}$ & $\begin{array}{r}1.056^{* * *} \\
(4.031)\end{array}$ \\
\hline POP/W & $\begin{array}{r}-0.619^{* * *} \\
(6.792)\end{array}$ & $\begin{array}{r}-0.624^{* * *} \\
(7.069)\end{array}$ & $\begin{array}{r}-0.625^{\star * *} \\
(7.161)\end{array}$ & $\begin{array}{l}-0.520 \\
(6.005)\end{array}$ & $\begin{array}{r}-0.349^{* * *} \\
(4.887)\end{array}$ \\
\hline World war casualties (t) & $\begin{array}{l}-9.439 \\
(0.210)\end{array}$ & $\begin{array}{l}12.680 \\
(0.278)\end{array}$ & $\begin{array}{l}11.601 \\
(0.257)\end{array}$ & $\begin{array}{l}52.450 \\
(1.183)\end{array}$ & $\begin{array}{l}46.318 \\
(1.321)\end{array}$ \\
\hline World war casualties (t-1) & & $\begin{array}{r}-13.320 \\
(0.307)\end{array}$ & $\begin{array}{r}4.107 \\
(0.091)\end{array}$ & $\begin{array}{l}38.118 \\
(0.881)\end{array}$ & $\begin{array}{l}29.432 \\
(0.860)\end{array}$ \\
\hline World war casualties (t-2) & & $\begin{array}{r}-56.671 \\
(1.310)\end{array}$ & $\begin{array}{r}-58.113 \\
(1.357)\end{array}$ & $\begin{array}{l}-4.451 \\
(0.103)\end{array}$ & $\begin{array}{r}-13.155 \\
(0.385)\end{array}$ \\
\hline World war casualties (t-3) & & $\begin{array}{r}-84.323^{*} \\
(1.785)\end{array}$ & $\begin{array}{r}-85.153^{*} \\
(1.821)\end{array}$ & $\begin{array}{r}-46.995 \\
(1.029)\end{array}$ & $\begin{array}{r}-51.798 \\
(1.432)\end{array}$ \\
\hline World war casualties (t-4) & & & $\begin{array}{l}-60.345 \\
(1.298)\end{array}$ & & \\
\hline$(G D P / W)^{2}$ & & & & $\begin{array}{r}0.041^{* * *} \\
(3.646)\end{array}$ & $\begin{array}{l}-0.007 \\
(0.578)\end{array}$ \\
\hline Post-1930 United States & & & & & $\begin{array}{r}42.263^{* * *} \\
(6.233)\end{array}$ \\
\hline$\sigma$ & $\begin{array}{l}12.051^{* * *} \\
(11.712)\end{array}$ & $\begin{array}{l}11.669^{* * *} \\
(11.709)\end{array}$ & $\begin{array}{l}11.553^{\star * *} \\
(11.714)\end{array}$ & $\begin{array}{r}10.989 \\
(11.799)\end{array}$ & $\begin{array}{l}8.701^{* * *} \\
(11.632)\end{array}$ \\
\hline Observations & 100 & 100 & 100 & 100 & 100 \\
\hline $\begin{array}{l}\text { Decomposition fit } \\
\text { measure }\end{array}$ & 0.47 & 0.51 & 0.52 & 0.61 & 0.76 \\
\hline
\end{tabular}

Note: Dependent variable is the prize share (in \%) per country-decade observation. The model is estimated with a Tobit methodology. T-statistics in parentheses; significance levels are $10 \% *, 5 \%$ $* *$ and $1 \% * * * \sigma$ is the estimated standard deviation of the error term. The decomposition fit measure is a goodness-of-fit measure for non-linear models (for details, see Greene, 2002). 


\section{References}

Becker Gary S. (1975). Human Capital: a theoretical and empirical analysis, with special reference to education, $2^{\text {nd }}$ edition, New York: NBER, distributed by Columbia University Press.

Bernard, Andrew B. and Meghan R. Busse. (2004). "Who Wins the Olympic Games: Economic Resources and Medal Totals." Review of Economics and Statistics 86(1), 413-417.

David, Paul A. (2000). "Path Dependence, Its Critics, and the Quest for 'Historical Economics'." Stanford University working paper \# 00-011.

Davis R. Donald and David E. Weinstein. (2002). "Bones, Bombs, and Break Points: The Geography of Economic Activity.” American Economic Review 92(5), 1269-1289.

Davis R. Donald and David E. Weinstein. (2004). "A Search for Multiple Equilibria in Urban Industrial Structure.” NBER working paper 10252.

Everhart, Stephen S. and Mariusz A. Sumlinski. (2001). “Trends in Private Investment in Developing Countries and the Impact on Private Investment of Corruption and the Quality of Public Investment" IFC discussion paper \#44. http://ifcln1.ifc.org/ifcext/economics.nsf/AttachmentsByTitle/dp44/\$FILE/dp44.pdf

Greene, William. (2002). LIMDEP Econometric Modeling Guide Volume 2. Plainview, NY: Econometric Software, Inc.

Jones, Benjamin F. (2005). Age and Great Invention. Manuscript.

Krugman, Paul. (1991). History versus Expectations. Quarterly Journal of Economics 106(2), 651-67.

Lucas, Robert E. Jr. (1976) “Econometric Policy Evaluation: a Critique.” In Karl Brunner and Allan H. Meltzer (Eds.), editors, The Phillips Curve and Labor Markets. Amsterdam: North-Holland Pub. Co., $19-46$.

Maddison, Angus. (2003). The World Economy: Historical Statistics. OECD: Paris.

Rose, Andrew K. (2006). “Size Really Doesn't Matter: In Search of a National Scale Effect.” NBER working paper \#12191.

Salter, Ammon J. and Ben R. Martin. (2001). "The Economic Benefits of Publicly Funded Basic Research: a Critical Review. Research Policy 30, 509-532.

Tanzi, Vito, and Hamid Davoodi. (1997). “Corruption, Public Investment, and Growth.” IMF Working Paper WP/37/139. Washington, D.C.

Weinberg, Bruce A. and David W. Galenson. (2005). "Creative Careers: The Life Cycles of Nobel Laureates in Economics.” NBER working paper \#11799.

Wuchty, Stefan, Jones, Benjamin and Brian Uzzi (2007). "The Increasing Dominance of Teams in the Production of Scientific Knowledge.” Science, forthcoming. 


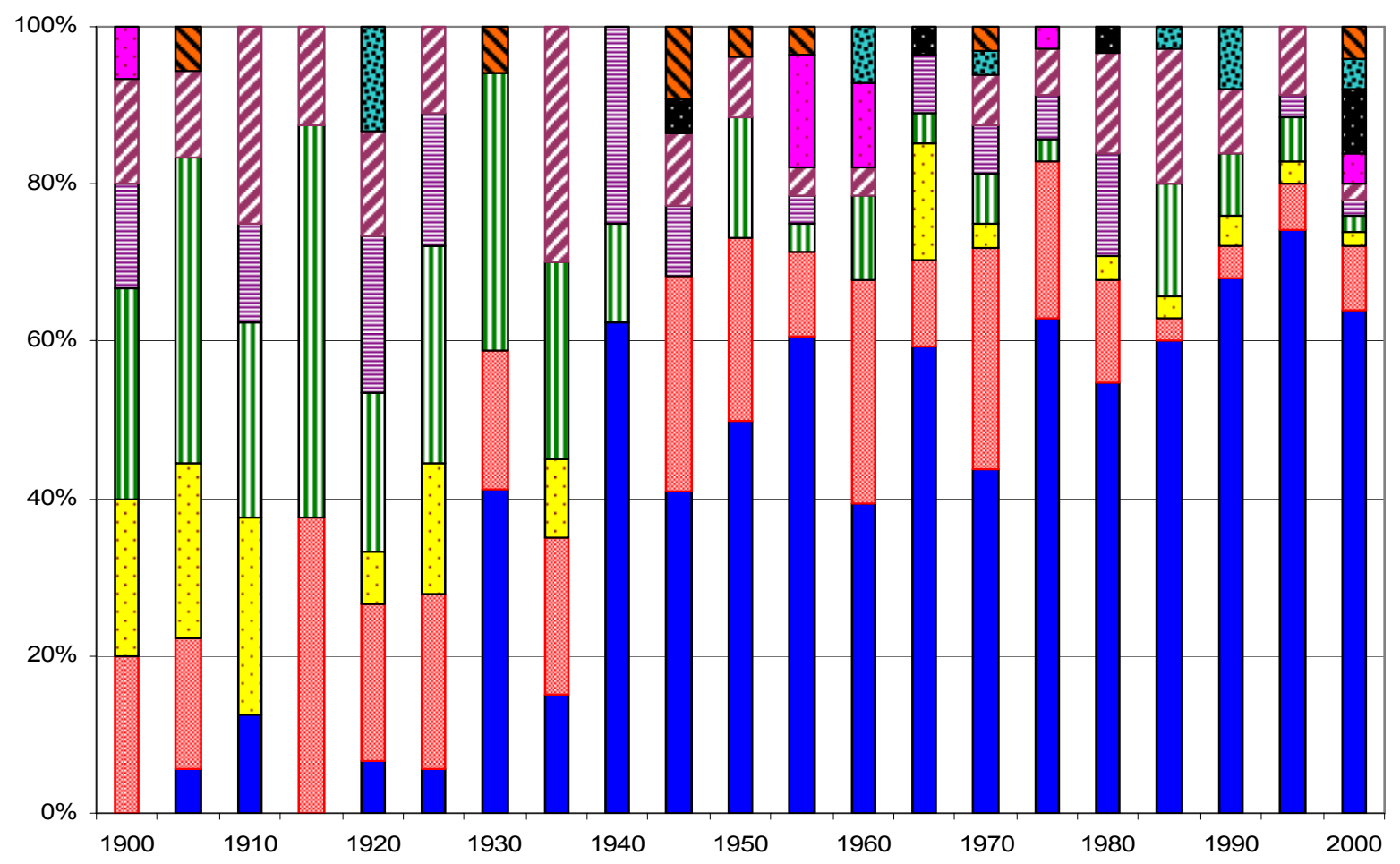

$\begin{array}{lll}\square \text { USA } & \square \text { UK } & \square \text { France } \\ \text { m Germany } & \text { 罗 Scandinavia } & \square \text { Europe (other) } \\ \square \text { USSR } & \square \text { Japan } & \text { Ganada \& Australia } \\ \text { D Other } & \end{array}$

Figure 1A: Nobel shares by country

Nobel shares (out of total science Nobels awarded) 1900-2005 


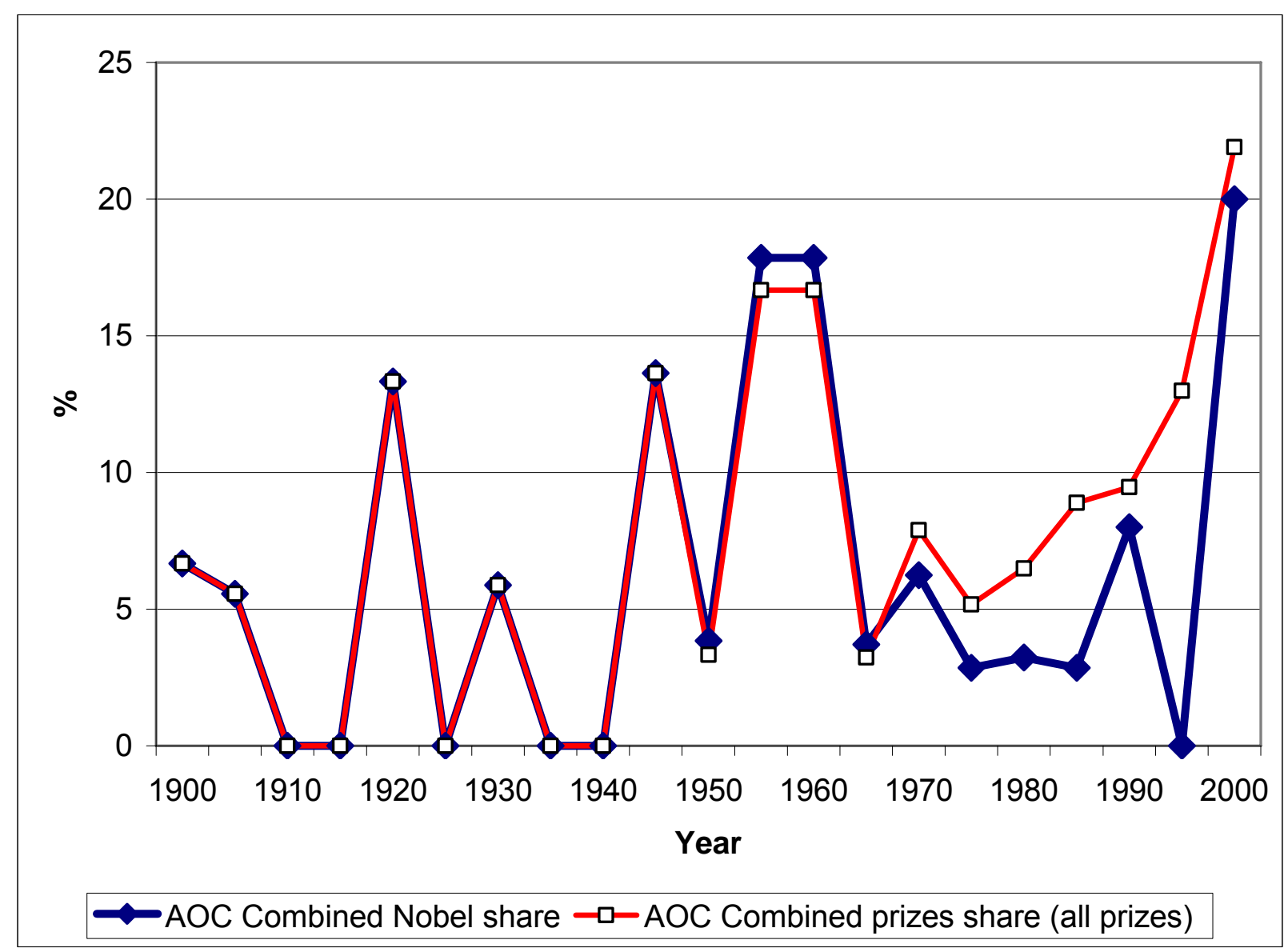

Figure 1B

Combined prize shares of AOC (all other countries, excepting Europe and the U.S.)

The blue curve plots AOC share of Nobel Prizes for basic science. The red curve plots AOC share of Nobel, Fields, Kyoto, and Wolf Prizes for basic research. 


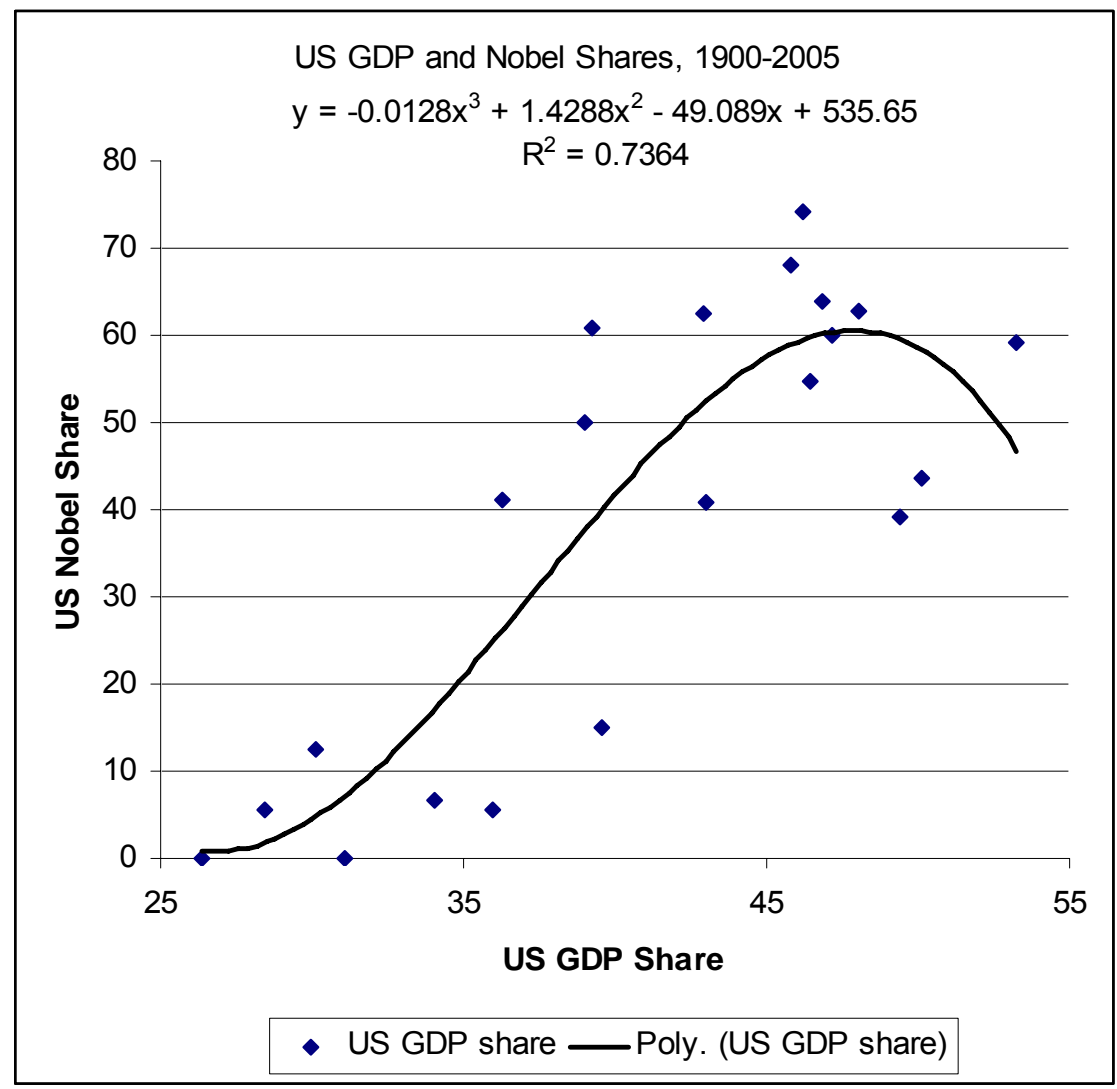

Figure 2: U.S. Nobel shares during the twentieth century and lagged U.S. share of World GDP The line corresponds to a third-order polynomial trend line 


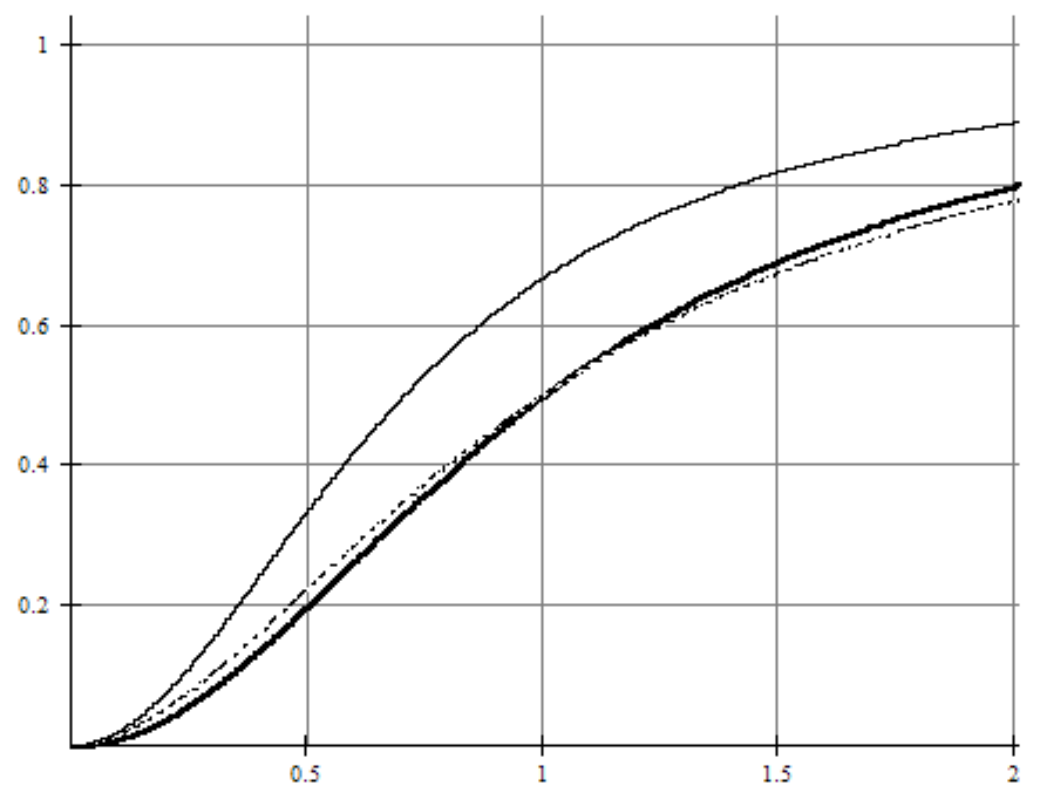

Figure 3A

U.S. prize share and the relative U.S./AOC GDP, with scale effects ( $\beta=2)$.

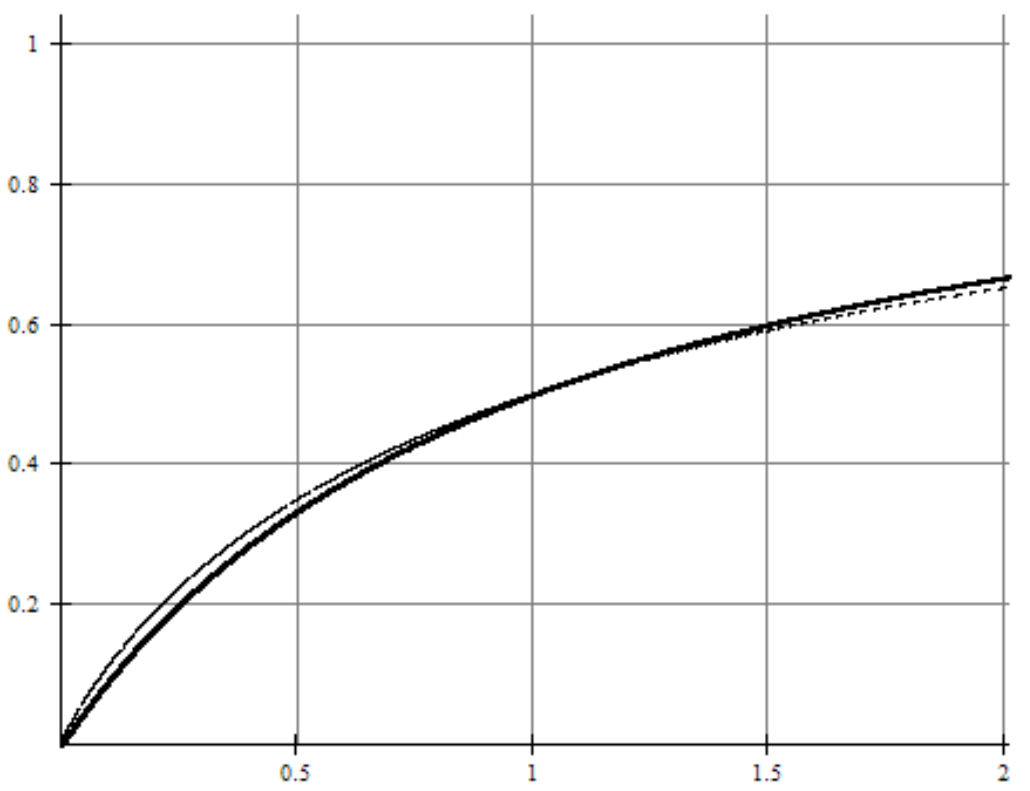

Figure 3B

\section{U.S. prize share and the relative U.S./AOC GDP, no scale effects ( $\beta=1)$.}

The bold curve corresponds to the base case: the absence of externalities associated with foreign human capital, where the AOC block is composed of one country $(a=1 ; n=1)$. The solid curve modifies the base case by assuming that the AOC block is composed of two symmetric countries $(a=1 ; n=2)$. The dotted curve modifies 
the base case by assuming modest externality where foreign human capital increases the efficacy of domestic human capital ( $a=0.95 ; n=1)$.

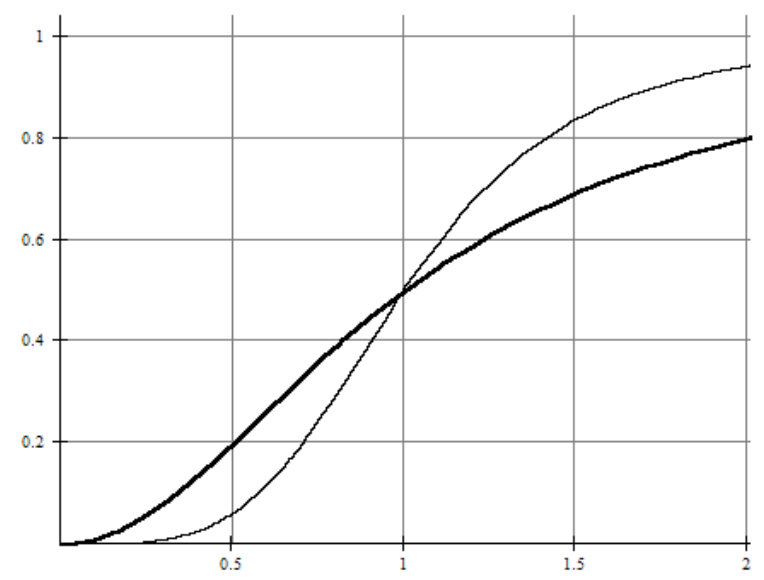

Figure 4A

AOC composed of one country

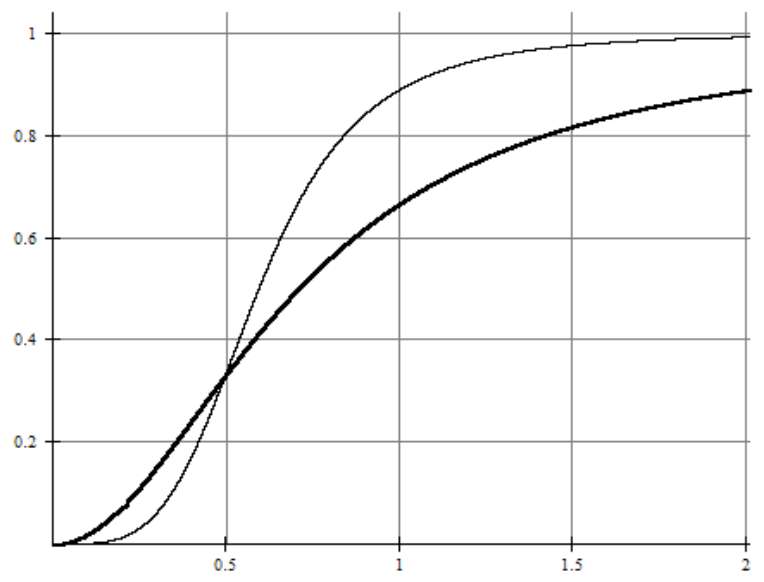

Figure 4B

AOC composed of two countries

\section{U.S. prize share and the relative U.S./AOC GDP, varying scale effects}

The bold curve corresponds to the base case of scale effect ( $\beta=2)$, and no externality associated with foreign human capital $(a=1)$. The dotted curve corresponds to magnified scale effects, $\beta=4, a=1$. The top panel assumes symmetry, where the AOC is, like the United States, composed on one country. The lower panel assumed fractured AOC, composed of two symmetric countries. 


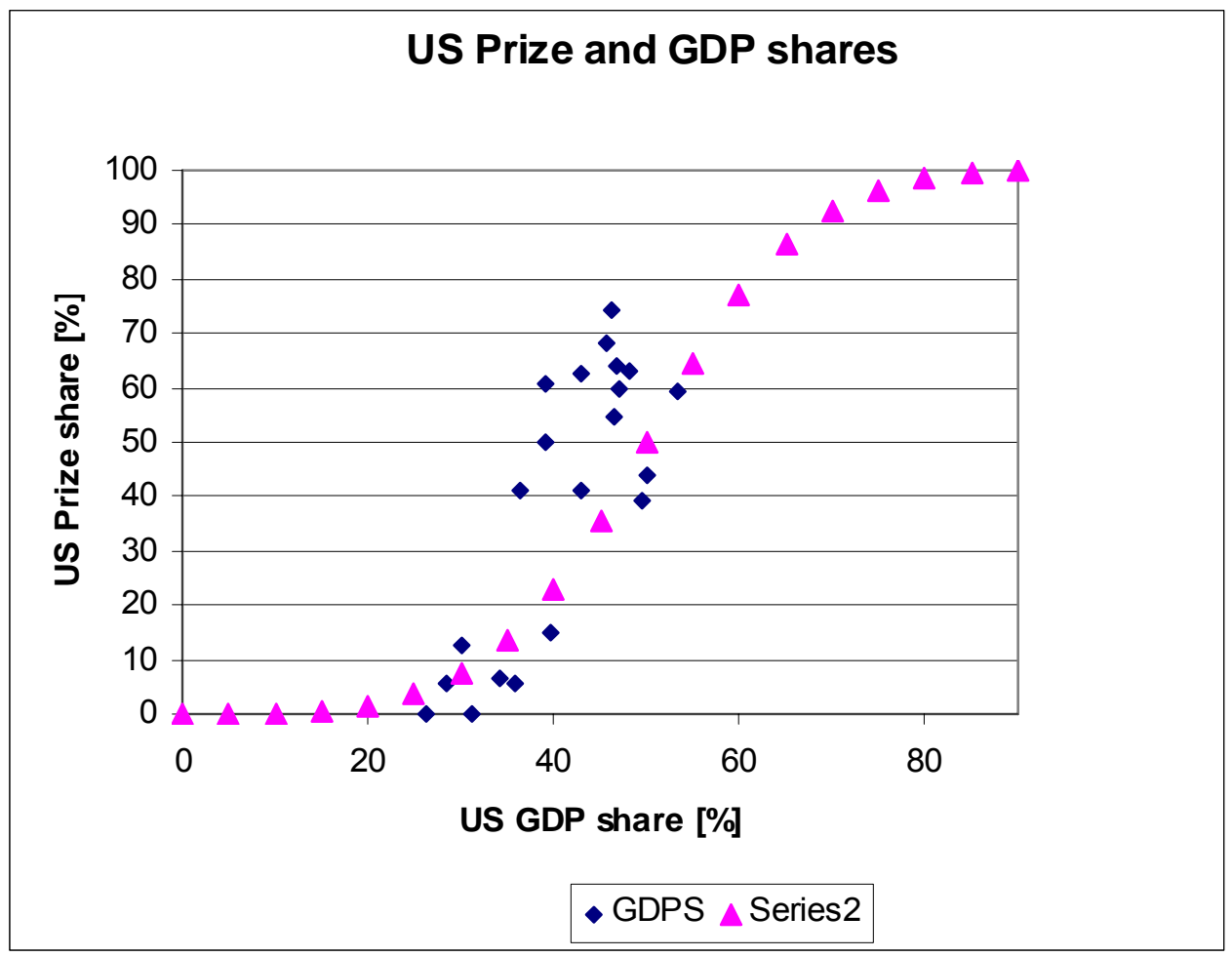

Figure 5

U.S. Nobel shares / lagged U.S. share of world GDP during the twentieth century

Series 2 (triangles) correspond to the simulated model [plotting equation (4'), for $\beta=3, n=1$ ] 


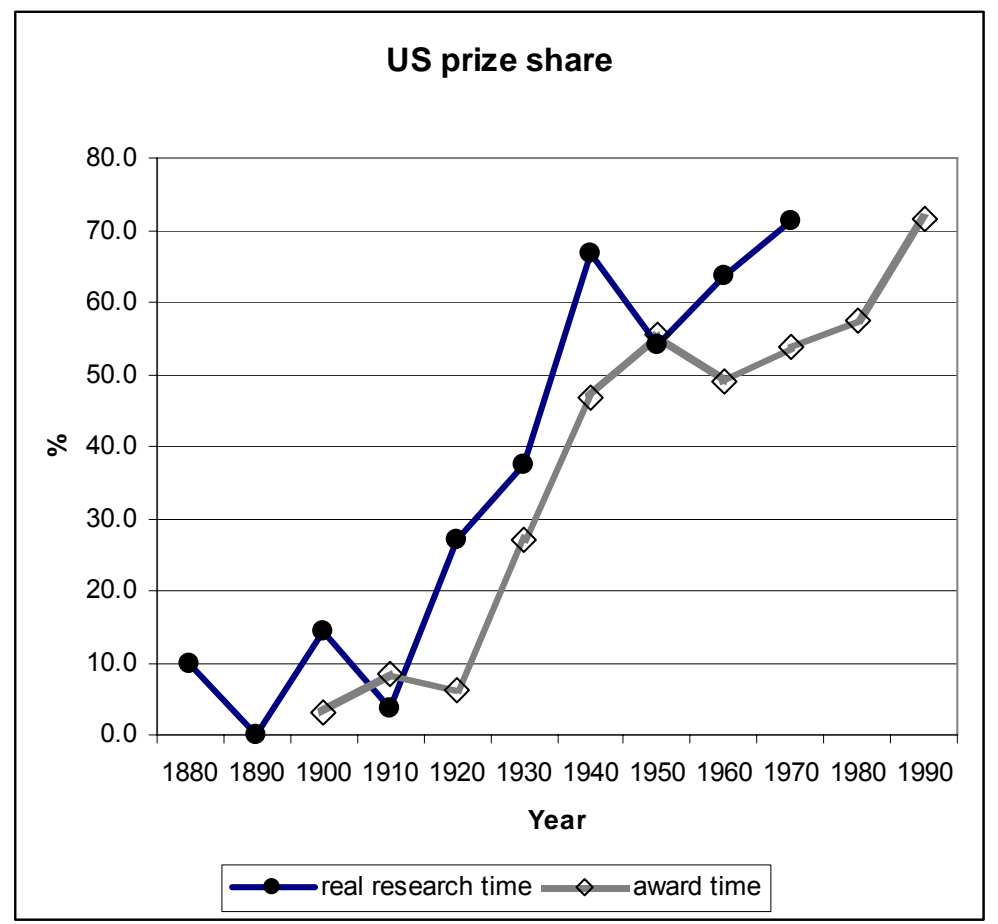

Figure 6a

U.S. Nobel Prize share, real research time (1880s-1970s), award time (1900s-1990s)

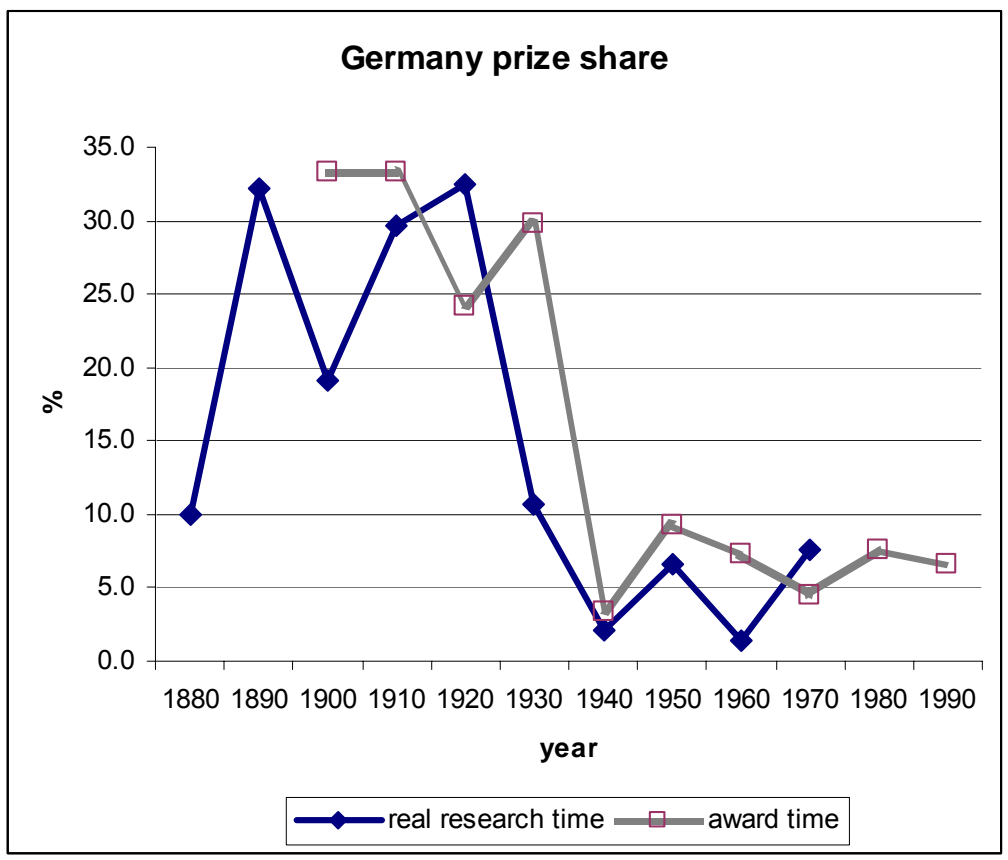

Figure 6b

Germany Prize share, real research time (1880s-1970s), award time (1900s-1990s) 


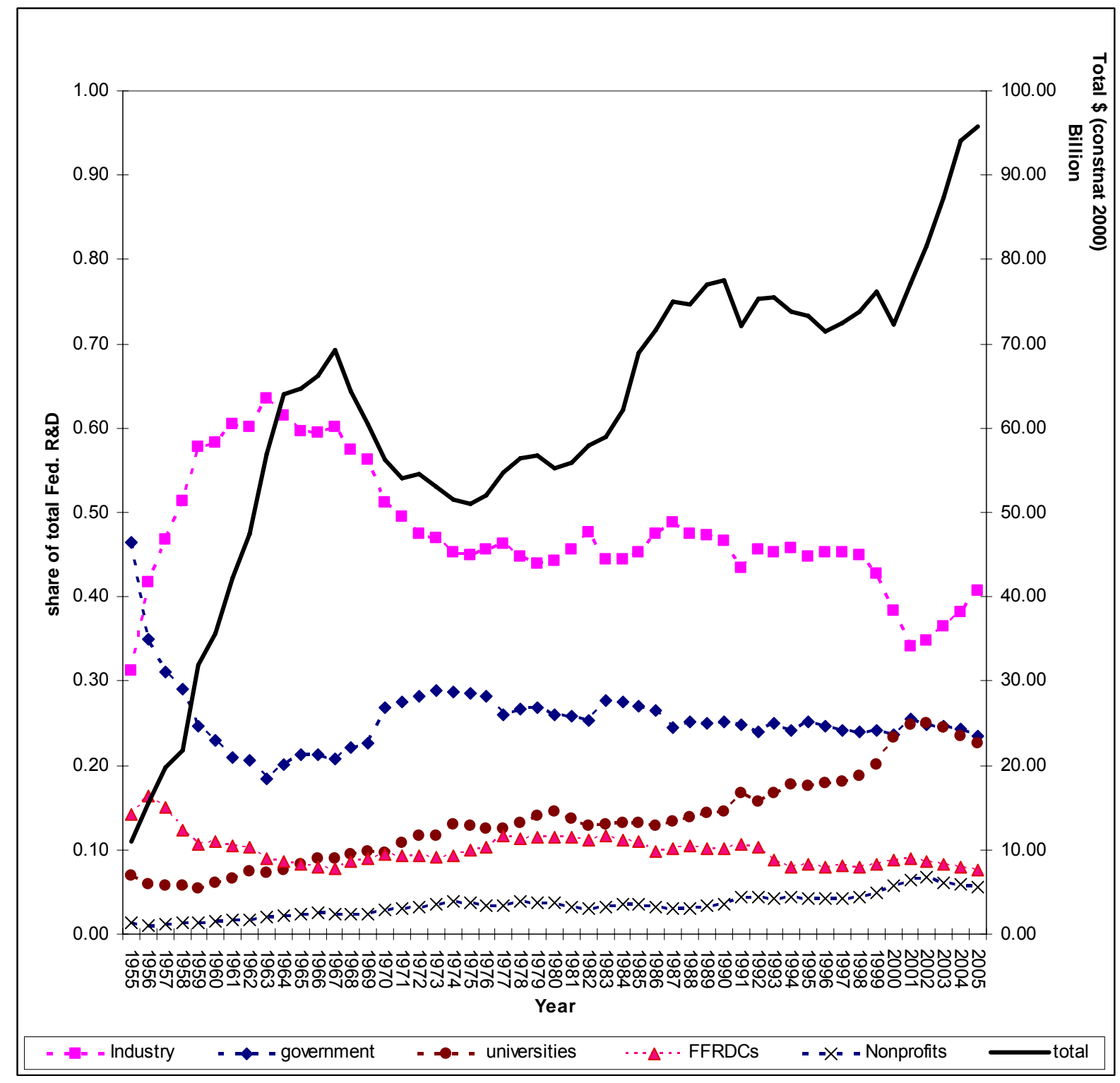

Figure 7

\section{Federal supported R\&D spending, 1955-2005 (total, and shares of R\&D preformed by various sectors)}

Right scale, the Solid curve: Total federal obligations for R\&D, FY 1955-2005; Constant 2000 (billions)

Left scale: Share of federal total obligations for R\&D supported by the government, by the performing sectors. The sectors, from top to bottom, are: Industry, Government R\&D, Universities, Federally Funded R\&D centers (FFRDC), and Non-profits. Source: Science and Engineering Indicators 2006 http://www.nsf.gov/statistics/seind06/c4/c4s2.htm 
Table 1A — Destinations for immigrant Nobel Prize winners (> 5)

\begin{tabular}{lcccc}
\hline & $1901-1935$ & $1936-1970$ & $1971-2005$ & Total \\
\hline United States & 3 & 29 & 44 & 76 \\
United Kingdom & 4 & 8 & 7 & 19 \\
Switzerland & 1 & 3 & 9 & 13 \\
Germany & 5 & 2 & 2 & 9 \\
France & 4 & 1 & 1 & 6
\end{tabular}

Number of prize-winners that immigrated to the destination countries listed in column 1.

Table 1B - Country of origin for immigrant Nobel Prize winners (> 5)

\begin{tabular}{lcccc}
\hline & $1901-1935$ & $1936-1970$ & $1971-2005$ & Total \\
\hline Germany & 2 & 12 & 14 & 28 \\
Austria & 3 & 5 & 3 & 11 \\
United Kingdom & 1 & 1 & 6 & 8 \\
Canada & 0 & 2 & 5 & 7 \\
Hungary & 1 & 3 & 3 & 7 \\
Poland & 2 & 2 & 3 & 7 \\
Russia & 1 & 2 & 2 & 5 \\
Italy & 1 & 2 & 3 & 6 \\
Netherlands & 1 & 1 & 3 & 5 \\
France & 2 & 2 & 1 & 5 \\
China & 0 & 3 & 2 & 5 \\
\hline
\end{tabular}

Number of prize-winners that emigrated from the countries-of-origin listed in column 1. 
Table 2A — Benchmark regression — research time ten-year data

\begin{tabular}{l|rrr|rrr}
\hline \multirow{2}{*}{ LHS: } & \multicolumn{3}{|c|}{ Nobel } & \multicolumn{3}{c}{ All Prizes } \\
& $(1)$ & $(2)$ & $(3)$ & $(4)$ & $(5)$ & $(6)$ \\
\hline \multirow{2}{*}{ GDP/W } & $1.021^{* * *}$ & & $1.622^{* * *}$ & $1.070^{* * *}$ & $\left(1.536^{* * *}\right.$ \\
& $(8.169)$ & & $(13.162)$ & $(10.515)$ & & $(14.910)$ \\
POP/W & & -0.057 & $-0.619^{* * *}$ & & 0.110 & $-0.456^{* * *}$ \\
& & $(0.453)$ & $(6.786)$ & & $(1.119)$ & $(6.958)$ \\
\hline$\sigma$ & $15.582^{* * *}$ & $22.562^{* * *}$ & $12.053^{* * *}$ & $12.905^{* * *}$ & $19.808^{* * *}$ & $10.214^{* * *}$ \\
Observations & $(11.549)$ & $(11.942)$ & $(11.712)$ & $(12.612)$ & $(12.834)$ & $(12.632)$ \\
Decomposition fit & 100 & 100 & 100 & 100 & 100 & 100 \\
measure & & & & & & \\
\hline
\end{tabular}

Note: Dependent variable is the prize share (in \%) per country-decade observation. The model is estimated with a Tobit methodology. T-statistics in parentheses; significance levels are $10 \% *, 5 \% * *$ and $1 \% * * * \sigma$ is the estimated standard deviation of the error term. The decomposition fit measure is a goodness-of-fit measure for non-linear models (for details see Greene, 2002).

Table 2B - Benchmark regression — award time five year data and lagged GDP/W

\begin{tabular}{l|rrr|rrr}
\hline \multirow{2}{*}{ LHS: } & \multicolumn{3}{|c|}{ Nobel } & \multicolumn{3}{c}{ All Prizes } \\
& $(1)$ & $(2)$ & $(3)$ & $(4)$ & $(5)$ & $(6)$ \\
\hline GDP/W (t-4) & $0.610^{* * *}$ & & $1.062^{* * *}$ & $0.673^{* * *}$ & $\left(1034^{* * *}\right.$ \\
& $(8.032)$ & & $(13.526)$ & $(10.742)$ & & $(15.773)$ \\
POP/W (t-4) & & -0.031 & $-0.176^{* * *}$ & & 0.012 & $-0.131^{* * *}$ \\
& & $(1.029)$ & $(7.107)$ & & $(0.523)$ & $(7.407)$ \\
\hline$\sigma$ & $18.240^{* * *}$ & $24.438^{* * *}$ & $14.814^{* * *}$ & $15.398^{* * *}$ & $21.700^{* * *}$ & $12.659^{* * *}$ \\
& $(14.549)$ & $(14.117)$ & $(14.662)$ & $(15.977)$ & $(16.583)$ & $(16.002)$ \\
Observations & 205 & 201 & 201 & 201 & 201 & 201 \\
Decomposition fit & & & & & & \\
measure & 0.18 & 0.21 & 0.34 & 0.20 & 0.15 & 0.38 \\
\hline
\end{tabular}

Note: Dependent variable is the prize share (in \%) per country - five-year observation. The model is estimated with a Tobit methodology. T-statistics in parentheses; significance levels are $10 \% *, 5 \% * *$ and $1 \% * * * . \sigma$ is the estimated standard deviation of the error term. The decomposition fit measure is a goodness-of-fit measure for non-linear models (for details see Greene, 2002). 
Table 3A — Scale regressions — research time ten-year data

\begin{tabular}{|c|c|c|c|c|c|c|}
\hline \multirow[t]{2}{*}{ LHS: } & \multicolumn{3}{|c|}{ Nobels } & \multicolumn{3}{|c|}{ All Prizes } \\
\hline & (1) & (2) & (3) & (4) & (5) & (6) \\
\hline GDP/W & $\begin{array}{l}0.674^{* *} \\
(2.533)\end{array}$ & $\begin{array}{r}0.849^{* * *} \\
(7.095)\end{array}$ & $\begin{array}{r}1.079^{* * *} \\
(4.901)\end{array}$ & $\begin{array}{r}0.782^{* * *} \\
(3.489)\end{array}$ & $\begin{array}{r}0.873^{* * *} \\
(8.439)\end{array}$ & $\begin{array}{r}1.120^{* * *} \\
(5.913)\end{array}$ \\
\hline POP/W & $\begin{array}{r}-0.529^{* * *} \\
(6.154)\end{array}$ & $\begin{array}{r}-0.318^{* * *} \\
(4.792)\end{array}$ & $\begin{array}{r}-0.354^{* * *} \\
(4.908)\end{array}$ & $\begin{array}{r}-0.395^{* * *} \\
(6.214)\end{array}$ & $\begin{array}{r}-0.236^{* * *} \\
(4.597)\end{array}$ & $\begin{array}{r}-0.263^{* * *} \\
(4.718)\end{array}$ \\
\hline Pre-1930 Germany & & $\begin{array}{r}15.984^{* * *} \\
(3.794)\end{array}$ & & & $\begin{array}{r}15.000^{* * *} \\
(4.062)\end{array}$ & \\
\hline Post-1930 United & & $41.962^{\star * *}$ & $42.189^{* * *}$ & & $36.366^{\star * *}$ & $37.469^{* * *}$ \\
\hline States & & $(8.830)$ & $(6.064)$ & & $(8.772)$ & $(6.185)$ \\
\hline Scandinavia & & $\begin{array}{r}2.174 \\
(0.800)\end{array}$ & & & $\begin{array}{r}1.943 \\
(0.817)\end{array}$ & \\
\hline$(\mathrm{GDP} / \mathrm{W})^{2}$ & $\begin{array}{r}0.039^{* * *} \\
(3.957)\end{array}$ & & $\begin{array}{l}-0.007 \\
(0.681)\end{array}$ & $\begin{array}{r}0.031^{* * *} \\
(3.743)\end{array}$ & & $\begin{array}{l}-0.009 \\
(0.958)\end{array}$ \\
\hline$\sigma$ & $\begin{array}{r}11.166^{\star \star *} \\
(11.803)\end{array}$ & $\begin{array}{l}8.182^{\star \star \star} \\
(11.682)\end{array}$ & $\begin{array}{l}8.934^{* * *} \\
(11.647)\end{array}$ & $\begin{array}{l}9.570^{* \star *} \\
(12.698)\end{array}$ & $\begin{array}{l}7.176^{\star \star \star} \\
(12.605)\end{array}$ & $\begin{array}{l}7.826^{\star \star \star} \\
(12.599)\end{array}$ \\
\hline Observations & 100 & 100 & 100 & 100 & 100 & 100 \\
\hline $\begin{array}{l}\text { Decomposition fit } \\
\text { measure }\end{array}$ & 0.60 & 0.79 & 0.75 & 0.64 & 0.81 & 0.77 \\
\hline
\end{tabular}

Note: Dependent variable is the prize share (in \%) per country-decade observation. The model is estimated with a Tobit methodology. T-statistics in parentheses; significance levels are $10 \% *, 5 \% * *$ and $1 \% * * * . \sigma$ is the estimated standard deviation of the error term. The decomposition fit measure is a goodness-of-fit measure for non-linear models (for details see Greene, 2002). 
Table 3B — Scale regressions — award time five-year data and lagged GDP/W

\begin{tabular}{|c|c|c|c|c|c|c|}
\hline \multirow[t]{2}{*}{ LHS: } & \multicolumn{3}{|c|}{ Nobels } & \multicolumn{3}{|c|}{ All Prizes } \\
\hline & (1) & (2) & (3) & (4) & (5) & (6) \\
\hline GDP/W (t-4) & $\begin{array}{l}0.362^{* *} \\
(2.080)\end{array}$ & $\begin{array}{r}0.582^{* * *} \\
(6.618)\end{array}$ & $\begin{array}{r}0.593^{* * *} \\
(3.452)\end{array}$ & $\begin{array}{r}0.502^{* * *} \\
(3.465)\end{array}$ & $\begin{array}{r}0.618^{* * *} \\
(8.457)\end{array}$ & $\begin{array}{r}0.716^{* * *} \\
(4.987)\end{array}$ \\
\hline POP/W (t-4) & $\begin{array}{r}-0.156^{* * *} \\
(6.465)\end{array}$ & $\begin{array}{r}-0.103^{* * *} \\
(5.005)\end{array}$ & $\begin{array}{r}-0.123^{* * *} \\
(5.223)\end{array}$ & $\begin{array}{r}-0.117^{* * *} \\
(6.702)\end{array}$ & $\begin{array}{r}-0.076^{* * *} \\
(5.022)\end{array}$ & $\begin{array}{r}-0.091^{\text {*** }} \\
(5.220)\end{array}$ \\
\hline Pre-1930 Germany & & $\begin{array}{r}24.069^{* * *} \\
(7.577)\end{array}$ & & & $\begin{array}{r}22.823^{* * *} \\
(6.196)\end{array}$ & \\
\hline Post-1930 United & & $35.104^{* * *}$ & $27.354^{\star \star *}$ & & $30.521^{* \star *}$ & $26.290^{\star * *}$ \\
\hline States & & (7.368) & (3.593) & & $(7.575)$ & $(4.051)$ \\
\hline Scandinavia & & $\begin{array}{r}1.970 \\
(0.715)\end{array}$ & & & $\begin{array}{r}3.011 \\
(1.318)\end{array}$ & \\
\hline$(G D P / W)^{2}(t-4)$ & $\begin{array}{r}0.022^{* * *} \\
(4.529)\end{array}$ & & $\begin{array}{r}0.004 \\
(0.684)\end{array}$ & $\begin{array}{r}0.017^{* * *} \\
(4.117)\end{array}$ & & $\begin{array}{r}0.000 \\
(0.054)\end{array}$ \\
\hline$\sigma$ & $\begin{array}{l}14.281^{\star \star *} \\
(14.762)\end{array}$ & $\begin{array}{r}11.783^{* * *} \\
(14.672)\end{array}$ & $\begin{array}{r}13.339^{\star * *} \\
(14.587)\end{array}$ & $\begin{array}{r}12.256^{* * *} \\
(16.089)\end{array}$ & $\begin{array}{r}10.072^{* \star *} \\
(16.020)\end{array}$ & $\begin{array}{r}11.461^{* \star \star} \\
(15.971)\end{array}$ \\
\hline Observations & 201 & 201 & 201 & 201 & 201 & 201 \\
\hline $\begin{array}{l}\text { Decomposition fit } \\
\text { measure }\end{array}$ & 0.46 & 0.60 & 0.52 & 0.49 & 0.65 & 0.56 \\
\hline
\end{tabular}

Note: Dependent variable is the prize share (in \%) per country-5-years observation. The model is estimated with a Tobit methodology. T-statistics in parentheses; significance levels are $10 \% *, 5 \% * *$ and $1 \%{ }^{* * *}$. $\sigma$ is the estimated standard deviation of the error term. The decomposition fit measure is a goodness-of-fit measure for non-linear models (for details see Greene, 2002). 
Table 4 - Regressions 1975-2004 — five-year award-time data and lagged GDP/W

\begin{tabular}{|c|c|c|c|}
\hline \multirow[t]{4}{*}{ 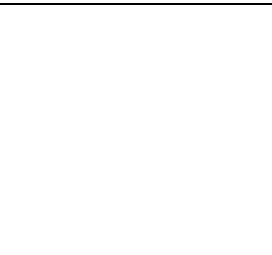 } & \multirow[t]{4}{*}{ LHS: } & \multicolumn{2}{|c|}{ All Prizes } \\
\hline & & (1) & (2) \\
\hline & & $1975-2004$ & $1900-2004$ \\
\hline & & & No United States \\
\hline \multirow{2}{*}{ GDP/W $\quad(\mathrm{t}-4)$} & & $0.717^{\star \star \star}$ & $0.685^{* * *}$ \\
\hline & & (4.461) & $(4.238)$ \\
\hline \multirow{2}{*}{$\mathrm{POP} / \mathrm{W} \quad(\mathrm{t}-4)$} & & $-0.148^{* * *}$ & $-0.114^{* * *}$ \\
\hline & & $(6.120)$ & $(4.879)$ \\
\hline \multirow{2}{*}{$(G D P / W)^{2} \quad(t-4)$} & & $0.009^{*}$ & 0.009 \\
\hline & & $(1.872)$ & $(0.948)$ \\
\hline
\end{tabular}

Interaction terms for post 1975 coefficients:

\begin{tabular}{lrr} 
& $-0.581^{*}$ \\
GDP/W $(p 1975)$ & $(1.937)$ & \\
& $0.063^{*}$ & \\
POP/W (p1975) & $(1.860)$ & \\
$(\mathrm{GDP} / \mathrm{W})^{2}(\mathrm{p} 1975)$ & $0.024^{\star * *}$ & $10.699^{* * *}$ \\
\hline$\sigma$ & $(2.895)$ & $(14.728)$ \\
Observations & $11.495^{\star * *}$ & 180 \\
Decomposition fit measure & $(15.997)$ & 0.13 \\
\hline
\end{tabular}

Note: Dependent variable is the prize share (in \%) per country - five-year observation. The model is estimated with a Tobit methodology. T-statistics in parentheses; significance levels are $10 \% *, 5 \% * *$ and $1 \% * * * . \sigma$ is the estimated standard deviation of the error term. The decomposition fit measure is a goodnessof-fit measure for non-linear models (for details see Greene, 2002). 